\section{Tocilizumab in patients with adult-onset Still's disease refractory to glucocorticoid treatment}

I was pleased to read the article by Kaneko and colleagues ${ }^{1}$ on the efficacy and safety of tocilizumab in patients with adult-onset Still's disease, because the current information on its biologic efficacy has been mainly obtained from small retrospective case series and not from prospective randomised trials. The authors have presented a randomised controlled trial in which they suggest that tocilizumab is effective in adult-onset Still's disease refractory to glucocorticoid treatment. Information on biologic therapy for the management of adult-onset Still's disease is scarce. In this regard, there is a noteworthy issue. At present, the treatment of patients with adult-onset Still's disease remains empirical. ${ }^{2}$ Corticosteroids are the cornerstones of the initial treatment, and conventional disease-modifying antirheumatic drugs (DMARDs), such as methotrexate, hydroxychloroquine, leflunomide, ciclosporin, tacrolimus and azathioprine, are generally used alone or in combination. DMARDs are effective means of inducing remission, lowering the risk of relapse and minimising glucocorticoid therapy and toxicity in adult-onset Still's disease. ${ }^{3}$ Thus, DMARDs are therapeutic options in addition to the standard-of-care treatment with glucocorticoids for this disease. ${ }^{4}$ Biologic agents are generally used as the secondline treatment because of their high cost and potential toxicity. ${ }^{5}$ Biologics may be considered in case of failure of DMARDs to control the disease. Although adult-onset Still's disease is a rare systemic inflammatory disorder, biologic therapy represents a major breakthrough in the management of patients with adult-onset Still's disease refractory to DMARDs. For example, anakinra induced more beneficial responses than DMARDs did in patients with refractory adult-onset Still's disease in a randomised study. ${ }^{6}$ However, there is no strong evidence regarding the comparative efficacy of tocilizumab and DMARDs in the management of adult-onset Still's disease. Currently, no randomised trial has shown that tocilizumab is superior to DMARDs in treating adult-onset Still's disease refractory to glucocorticoid treatment. Thus, treatment for adult-onset Still's disease continues to be a challenge. Further randomised studies are warranted to determine the benefits of tocilizumab in terms of its glucocorticoid-sparing effect, remission and reduction in relapse, compared with DMARD therapy.

\section{Young Ho Lee}

Correspondence to Professor Young Ho Lee, Division of Rheumatology, Korea University Medical Center, Seoul 02841, South Korea; lyhcgh@korea.ac.kr

Competing interests None declared.

Patient consent Not required.

Provenance and peer review Not commissioned; internally peer reviewed.

(c) Author(s) (or their employer(s)) 2019. No commercial re-use. See rights and permissions. Published by BMJ.

A) Check for updates

To cite Lee YH. Ann Rheum Dis 2019;78:e133.

Received 23 October 2018

Accepted 26 October 2018

Published Online First 2 November 2018

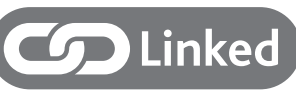

http://dx.doi.org/10.1136/annrheumdis-2018-214653

Ann Rheum Dis 2019;78:e133. doi:10.1136/annrheumdis-2018-214635

\section{REFERENCES}

1 Kaneko Y, Kameda H, Ikeda K, et al. Tocilizumab in patients with adult-onset still's disease refractory to glucocorticoid treatment: a randomised, double-blind, placebocontrolled phase III trial. Ann Rheum Dis 2017;77:1720-9.

2 Castañeda S, Blanco R, González-Gay MA. Adult-onset Still's disease: advances in the treatment. Best Pract Res Clin Rheumatol 2016;30:222-38.

3 Yoo DH. Treatment of adult-onset still's disease: up to date. Expert Rev Clin Immunol 2017;13:849-66.

4 Kalyoncu U, Solmaz D, Emmungil H, et al. Response rate of initial conventional treatments, disease course, and related factors of patients with adult-onset Still's disease: data from a large multicenter cohort. J Autoimmun 2016;69:59-63.

5 Pasadhika S, Rosenbaum JT. Update on the use of systemic biologic agents in the treatment of noninfectious uveitis. Biologics 2014;8:67.

6 Nordström D, Knight A, Luukkainen R, et al. Beneficial effect of interleukin 1 inhibition with anakinra in adult-onset Still's disease. An open, randomized, multicenter study. J Rheumatol 2012;39:2008-11. 